Article

\title{
Vibration Measurement Using Laser Triangulation for Applications in Wind Turbine Blades
}

\author{
Víctor Iván Moreno-Oliva ${ }^{1}{ }^{(D}$, Ociel Flores-Diaz $^{2}$, Edwin Román-Hernández ${ }^{1}\left({ }^{(0}\right.$, Manuel Campos-García ${ }^{3}$, \\ Eduardo Campos-Mercado ${ }^{2}$, José Rafael Dorrego-Portela ${ }^{1}$, Quetzalcoatl Hernandez-Escobedo ${ }^{4, *} \mathbb{B}$, \\ Jesus Alejandro Franco ${ }^{4}\left(\mathbb{D}\right.$, Alberto-Jesus Perea-Moreno ${ }^{5, *}{ }^{(\mathbb{C}}$ and Alfredo Alcayde García ${ }^{6, *}$ (i)
}

1 División de Estudios de Posgrado, Universidad del Istmo, 70760 Oaxaca, Mexico; vmorenofcfm@hotmail.com or ivan.moreno@sandunga.unistmo.edu.mx (V.I.M.-O.); rohe_00@hotmail.com or eroman@sandunga.unistmo.edu.mx (E.R.-H.); r.dorrego.63@hotmail.com or r.dorrego@sandunga.unistmo.edu.mx (J.R.D.-P.)

2 CONACYT-Universidad del Istmo, 70760 Oaxaca, Mexico; ocielfd@gmail.com or oflores@conacyt.mx (O.F.-D.); ecampos@conacyt.mx (E.C.-M.)

3 Instituto de Ciencias Aplicadas y Tecnología, Universidad Nacional Autónoma de Mexico, Ciudad Universitaria, 04510 Mexico City, Mexico; manuel.campos@icat.unam.mx

4 Escuela Nacional de Estudios Superiores Unidad Juriquilla, UNAM, 76230 Queretaro, Mexico; alejandro.francop@unam.mx

5 Departamento de Física Aplicada, Radiología y Medicina Física, Universidad de Córdoba, Campus de Rabanales, 14071 Córdoba, Spain

Citation: Moreno-Oliva, V.I.

Flores-Diaz, O.; Román-Hernández,

E.; Campos-García, M.;

Campos-Mercado, E.;

Dorrego-Portela, J.R.;

Hernandez-Escobedo, Q.; Franco, J.A.;

Perea-Moreno, A.-J.; García, A.A.

Vibration Measurement Using Laser

Triangulation for Applications in Wind Turbine Blades. Symmetry 2021,

13, 1017. https://doi.org/10.3390/ sym13061017

Academic Editor:

Konstantin Zhukovsky

Received: 8 May 2021

Accepted: 3 June 2021

Published: 6 June 2021

Publisher's Note: MDPI stays neutral with regard to jurisdictional claims in published maps and institutional affiliations.

Copyright: (C) 2021 by the authors Licensee MDPI, Basel, Switzerland. This article is an open access article distributed under the terms and conditions of the Creative Commons Attribution (CC BY) license (https:/ / creativecommons.org/licenses/by/ $4.0 /)$.
6 Department of Engineering, University of Almería, La Cañada de San Urbano, 04120 Almería, Spain

* Correspondence: qhernandez@unam.mx (Q.H.-E.); aperea@uco.es (A.-J.P.-M.); aalcayde@ual.es (A.A.G.)

\begin{abstract}
The blades in a wind turbine are currently manufactured with flexible and light materials, which make them more susceptible to the effects of vibrations when the wind speed is high enough, causing fatigue damage, affecting the functionality of its structure and aerodynamic efficiency. This work presents a comparison of the modal vibration parameters, applied to a cantilever beam, determined with two experimental methods-the use of accelerometers and a proposed optical non-contact method-based on the principle of laser triangulation and photogrammetry techniques. This technique uses the geometric symmetry of the equidistant displacements along the $\mathrm{z}$ axis of the beam to obtain the amplitude data. Parameters such as natural frequency and modal form are obtained by fitting the data to a nonlinear equation with a solution which is an exponential/harmonic equation. Also, analytically, these parameters are determined, and a comparison is made between the experimental methods. The result shows that the relative error of the first-order natural vibration frequency is below $1 \%$. The proposed method is simple, efficient, reliable, and it is also a method that has not been applied to the test of wind turbine blades, so its implementation as this type of wind turbine component is an area of opportunity for the validation of modal vibration parameters in the wind industry. An analysis of results is presented showing benefits of the proposed method and its limitations.
\end{abstract}

Keywords: vibration; laser triangulation; wind turbine blades

\section{Introduction}

Recently, there has been increasing interest in the development of techniques and tools that can provide global information on the dynamics of structures and components exposed to constant stress, as well as to validate and update analytical models. Several authors have presented many methods to measure the frequency and amplitude of vibrations using mechanical [1], electrical [2], or optical devices [3,4], which depend on the need for physical contact with the object or not. Accelerometers are by far the most traditional and widely-used sensors used in modal testing; their ease of use allows for quick broadband measurements to be made, yet one must consider the effects of (1) mass-loading, especially 
at higher frequency ranges; although progress in downsizing these devices is currently under continuous development [5]; (2) short spatial information only because a contact transducer provides information only from one measurement point, in this case, the point on the object where the sensor is placed [6]; and (3) difficulty in selecting an appropriate mechanical stressing device, especially in the case of a large structure with complex geometry [7].

Optical techniques have the advantage of being non-invasive and offer in most cases an alternative for the measurement of lateral displacements. These optical techniques employ devices such as laser vibrometers, fiber optic sensors, laser triangulation, and photogrammetry techniques, which provide better results in static and dynamic configuration tests for the measurement of modal parameters in low-power wind turbine blades, as in the case of this application proposal.

Metrology of vibration measurements by laser techniques, as performed by HansJürgen [8], has been presented in several documents and contributions at international conferences in this area. There have been many specific sessions on metrology, calibration, and standards focused on presenting and discussing innovative methods, techniques, procedures, experimental results, and international standards, developed at the National Institutes of Metrology (NIM) and the International Organizations for Metrology or Standardization [9-11].

Proulx, T. 2011 [9] presents experimental and computational research in an important area of structural dynamics, including studies on wind turbine blades, dynamics, and modal analysis applied to wind turbines, among other topics.

Laser vibrometers [12-14] have many advantages over similar devices used to measure vibrations such as accelerometers. Most laser vibrometers have unparalleled performance and capability testing tools built-in, high sensitivity and spatial resolution, and can automate testing processes to test different points of a structure. Laser vibrometer configurations also reduce measurement time and allow testing of those points on the testing structure where conventional sensors cannot be placed. A disadvantage of these vibration measurement devices is the high cost.

Fiber optic measurements [15,16] offer a solution, but have the disadvantage of being sensitive to temperature changes, and error compensation methods still require further investigation. Optical and laser triangulation techniques (LTT) [17-21] are the most used procedure for the reconstruction of 3D objects because they are based on triangulation between the object, the CMOS or CCD and the projection of laser light. Height changes in the reconstruction of a profile are measured from the lateral displacements of the light projected on the object under test, and generally the projection has a linear structure, which is achieved by refraction in a cylindrical lens. Furthermore, LTT have a simple arrangement and fast measurement speed, so there exists a wide range of applications in the inspection and quality control of the production process [22-29]. An interesting contribution of this technique is shown in reference [22], where the use of LTT in the reconstruction of aerodynamic profiles for quality tests on wind turbine blades is presented.

However, the main disadvantage of LTT is the requirement for non-external light sources and a set of color requirements of the surface under test, such that if this is not possible in the experimental setup, an additional image processing method is required to obtain the digital reconstruction of the object geometry.

In recent years, there has been an increase in research on non-contact measurement techniques, such as photogrammetry and digital image correlation (DIC) [30-34], and more recently these techniques have been used and applied to the field of experimental mechanics [35], the aerospace industry [36], measurement of shapes 3D [37], civil engineering [38-40], and bridge inspection [41]. By improving the technologies and production of new high-speed cameras, researchers have recently begun to use optical techniques to measure vibrations.

Some published works are related to our proposal; for instance, Wu et al., 2007 [18] developed an application of the laser triangulation technique that is presented, for the 
measurement of arterial frequency in a frequency range between 1.27 and $1.35 \mathrm{~Hz}$, and arterial pulse amplitudes between 38 and $48 \mu \mathrm{m}$, with a measurement resolution better than $4 \mu \mathrm{m}$ and an error of less than $3 \%$ compared to a commercial blood pressure monitor. In [19], the authors propose an alternative way for the quantitative measurement of animal algesia, determining changes in muscle vibration, with an accuracy of $10 \mu \mathrm{m}$; they use a horn with a signal generator to validate their results and errors, in a frequency range between 0.6 and $2 \mathrm{~Hz}$ with an error of less than 3\%. A review of the different optical methods for measuring distance and displacements is shown in the work of Berkovic and Shafir, 2012 [42]. In this work the authors affirm that triangulation sensors have been used for a long time and, depending on the application, their main advantage is their low cost and quick implementation for measurement; also, the sensitivity range of these devices is from $10 \mathrm{~mm}$ to $1 \mathrm{~m}$, and the resolution depends on the detection distance; as the maximum detection distance increases, the resolution decreases progressively; the size of the laser beam and the size of the detection pixel are other factors that can modify this resolution, but resolutions of several micrometers can be obtained. Wang et al., 2019 [6] report the application of a novel technique using binocular photogrammetry for irregular structures and apply it in order to test ther blade of a wind turbine; their results are compared with the use of accelerometers with an error of $1.3 \%$.

The proposal presented in this work is a hybrid optical technique that employs a combination of LTT and photogrammetry techniques and, by means of image processing, the information is reconstructed for analysis. In addition, symmetrical patterns have been used in this work to obtain the centroid. The implementation of the proposed method is simple compared to other methods and can be applied to the dynamic testing of large wind turbine blades.

It is important to mention that the disadvantages of the proposed method are (a) the low sampling rate, as it does not have a high-speed camera, the frequency spectrum does not contain other frequencies other than the natural frequency; (b) Laboratory tests must be carried out under certain lighting conditions, in such a way that external light sources do not influence the estimation of the projected laser spot centroid. On the other hand, the advantages of the method are: (a) the technique is non-invasive and optical contact, so no additional masses are added, such as that of the transducers, and it is not necessary to add marks as in photogrammetry techniques, which makes it a faster test when measuring points of interest along the blade under test; (b) Another advantage is the low cost compared to measurement equipment that uses accelerometers.

The article is organized into four sections, beginning with the introduction, where a description of the state of the art is made; in Section 2 we add three subsections, in Section 2.1 we describe the analytical method; in Section 2.2 we describe the optical technique and calibration process, and in Section 2.3 we describe the dynamic analysis of a cantilever beam determined with two experimental methods, the use of accelerometers and the proposed optical technique; Section 3 presents the results and discussion of the techniques used and the experimental application to the blade of a wind turbine; and finally, the conclusions of the work are developed.

\section{Materials and Methods}

\subsection{Lateral Vibrations of Beams: Analytical Method}

The natural frequency, mode shape and damping coefficient are the three parameters required to perform the dynamic characterization of mechanical systems. For a continuousmass fixed-free beam with length $L$, uniform cross-section area $A$, moment of inertia with respect to the centroid of the cross-section area $I$, modulus of elasticity $E$, mass density over unit volume uniform $\rho$. From the thin beam theory, the natural frequencies of the beam are determined by

$$
\omega_{n}=\left(\beta_{n} L\right)^{2}\left(\frac{E I}{\rho A L^{4}}\right)^{1 / 2}, n=1,2, \ldots
$$


where $\beta_{n} L$ are the roots of

$$
\cos \beta_{n} L \cosh \beta_{n} L=-1
$$

On the other hand, the mode shapes can be determined by the product of two functions, temporal $T(t)$ and spatial $W(x)$ functions, that is

$$
\omega(x, t)=W(x) T(t)
$$

where for the $n_{t h}$ mode shape, $W_{n}(x)$ and $T_{n}(t)$ are

$$
\begin{gathered}
W(x)=c_{n}\left[\cos \beta_{n} x-\cosh \beta_{n} x-\frac{\cos \beta_{n} L+\cosh \beta_{n} L}{\sin \beta_{n} L+\sinh \beta_{n} L}\left(\sin \beta_{n} x+\sinh \beta_{n} x\right)\right] \\
T_{n}(t)=A_{n} \cos \omega_{n} t+B_{n} \sin \omega_{n} t
\end{gathered}
$$

A particular vibration is produced by the specified initial conditions,

$$
\omega(x, 0)=\omega_{0}(x), \frac{d \omega(x, 0)}{d t}=\dot{\omega}_{0}(x)
$$

For our study case $\dot{\omega}_{0}(x)=0$. Evaluating (3) at $t=0$, and matching the first initial condition (5),

$$
c_{n} W_{n}(x) A_{n}=\omega_{0}(x)
$$

Taking $D_{n}=c_{n} A_{n}$ and assuming that $\omega_{0}(x)$ is an integrable function on the interval $[0, L]$, we obtain.

$$
D_{n}=\frac{\int_{0}^{L} \omega_{0}(x) W_{n}(x) d x}{\int_{0}^{L}\left(W_{n}(x)\right)^{2} d x}
$$

With the resolution of Equation (7), the $n_{t h}$ mode shape of vibration of our problem is defined.

Among the different types of damping that exist in mechanical systems, the one that corresponds to a fixed-free beam that is made to vibrate freely is hysteresis damping. It is due to friction between the internal planes when they slide as the material deforms. There are different procedures to determine this damping coefficient; for example, using the deformation energy concept, the equivalent mass concept, among other ways.

The energy dissipated by the damping in one cycle of motion is given by [43-45]:

$$
\Delta W=\oint F d x=\pi h X^{2}
$$

where $h$ is the hysteresis damping constant, $h=\omega c, \omega$ is the natural frequency, $c$ the damping coefficient and $X$ is the maximum deflection amplitude.

On the other hand, the energy lost in a cycle can be determined through the deformation energy due to the bending moment $(M)$ given the application of a load $(P)$ at the end, that is [46].

$$
U_{i}=\int_{0}^{L} \frac{M^{2}}{2 E I} d x
$$

With the determination of $U_{i}$ and $U_{(i+1)}, \Delta W$ is computed. With this, the determination of the damping coefficient is completely defined.

It is important to mention that the damping coefficient determined through (8) and (9) is for the linear elastic range since (9) was determined from Hooke's Law. If it is required to work in the nonlinear elastic range, it is necessary to remove this restriction and determine a new expression for the strain energy (9).

\subsection{Optical Technique}

The optical methodology takes advantage of the properties of geometric and mechanical symmetry in structures to reduce the size of the models to be analyzed with a computer. The measurement system calculates the symmetric displacements along the $\mathrm{Z}$ axis by the 
projection and observation system on the $\mathrm{Z}$ axis. This optical technique can be adapted to systems with symmetric or equidistant displacement along a specific direction.

The optical technique implemented in this work is based on laser triangulation techniques, which are commonly used in industry for inspection and quality control, have a simple structure, fast measurement, and easily interpreted results. The scheme in Figure 1 shows the experimental setup used to determine the mechanical displacement of a slim cantilever beam. This is based on the projection of a laser spot on the surface of the cantilever beam at a point $P(x, y, z)$. Here a camera forms an angle $\alpha$ to the beam plane and captures the image of the spot on the surface at the center of the image plane in $P_{0}\left(x_{0}, y_{0}, z_{0}\right)$ when the beam is in a static configuration (reference system). If a disturbance is applied to the beam, it begins to vibrate in the direction of the $Z$ axis of the reference system, and these mechanical displacements are observed in the Figure 1 as lateral displacements $\Delta x$.

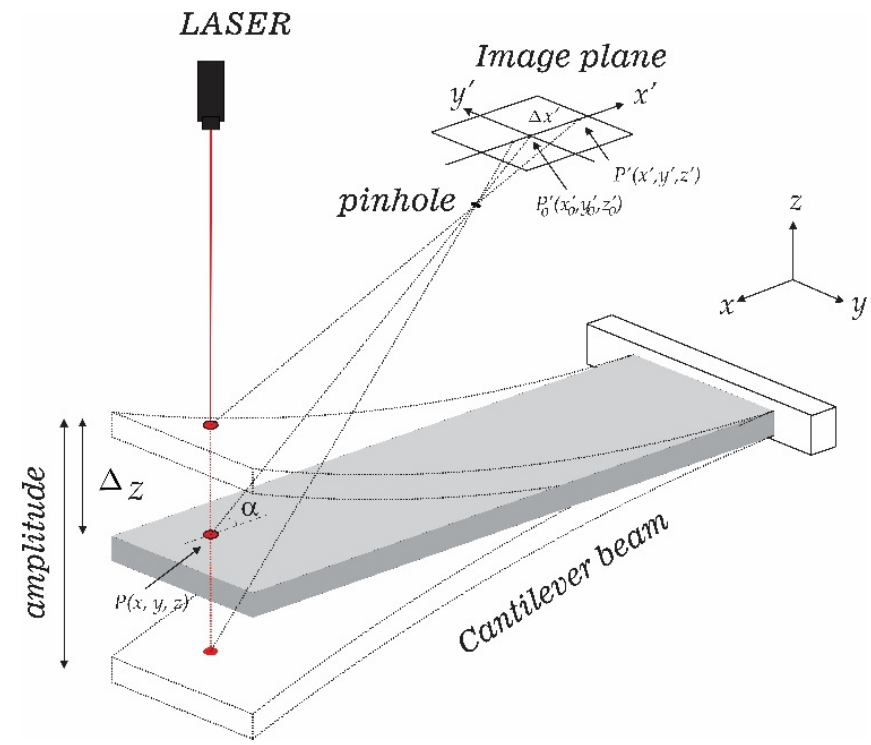

Figure 1. Basic optical measurement scheme for reconstructing vibration trajectory on a cantilever beam.

A mathematical expression associates the changes of height $\Delta z$ with the observed lateral displacements $\Delta x^{\prime}$, knowing in advance the parameters such as the distance from the image plane to the pinhole $k$, the distance from the pinhole to the plane of the beam $r$, and the angle of camera observation $\alpha$, as in reference [22] we have

$$
\Delta z=\frac{r \Delta x^{\prime}}{\Delta x^{\prime}+k \cot \alpha}
$$

The methodology for the reconstruction of the vibration trajectory is based on the measurement of each displacement of the beam $\Delta z$ in a time interval $\Delta t$ by means of the frame-by-frame decomposition of the capture of a video of the lateral displacements observed in the image plane. Each image obtained is processed and the centroid of the laser spot image is evaluated.

Experimentally, measuring the parameters involved in Equation (10) is not very practical, so the use of a calibration process of the optical measurement system is conveniently used, i.e., the motorized linear displacement stage travels known equidistant displacements along the $z$ axis, and these displacements are observed in the image plane (Figure 1) of the camera as transverse displacements and are measured in pixels. For each displacement, the image of the projected laser spot is captured and the position of the centroid is computed; in this way, a calibration curve is constructed (Figure 2), which allows a conversion of pixel units to millimeters of the measurements made, as well as the sensitivity of the measuring 
instrument on the $z$ axis; that is, the minimum amplitude of vibration that can be measured if we consider that the smallest measurable unit in the image plane is of the order of 1 pixel.

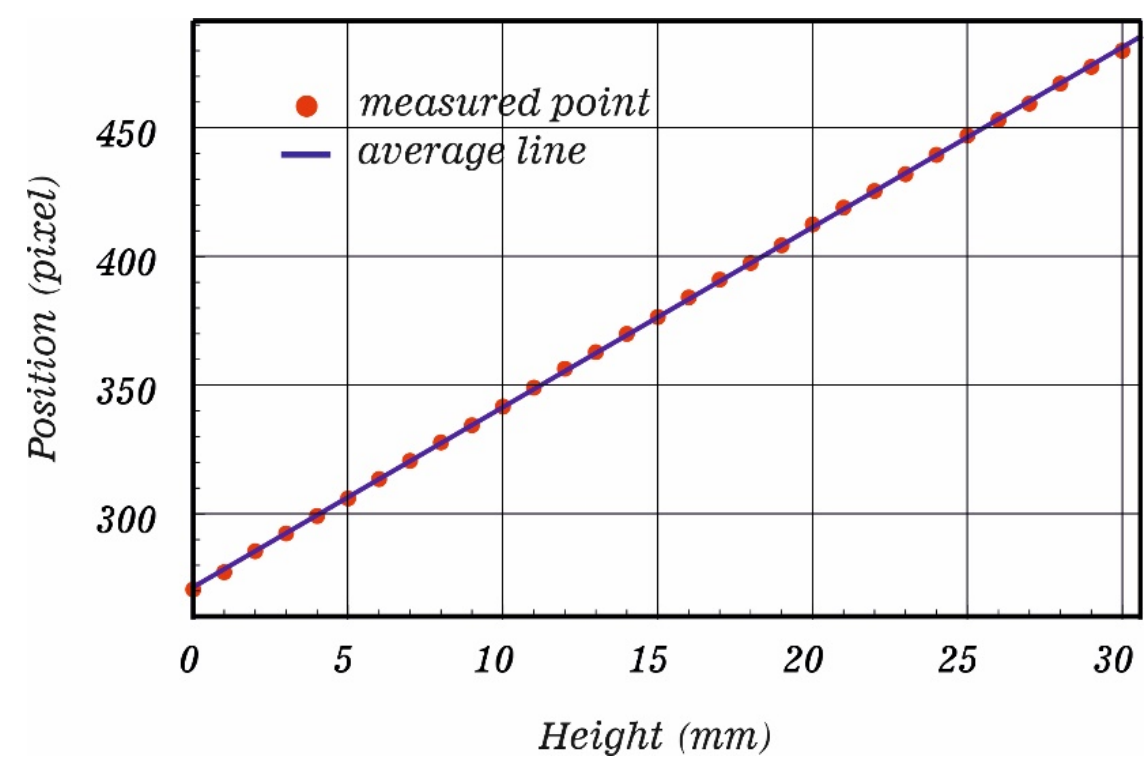

Figure 2. Calibration curve measured for unit conversion and determination of the sensitivity and linearity of the method.

Due to the calibration curve obtained, we can measure changes in height on the $Z$ axis of the order of $0.1 \mathrm{~mm}$. On the other hand, using the information about of the discrepancies of the experimental data of the calibration curve and the corresponding equation of the fitted line, the error of the instrument was determined to detect these changes in height of the order of $1 / 2$ pixel, which is equivalent to obtain an error in the measure or tolerance of $\pm 0.05 \mathrm{~mm}$.

If a higher resolution camera is used, the results can be improved; the main drawback is that it becomes in a non-cost-effective technique. However, another option is to modify the measurement scheme diminishing the angle $\alpha$ of the camera, in such a way that the sensitivity of the lateral displacements observed in the image plane of the camera can be increased for small change height of the cantilever beam. The drawback is that there is a limit to the camera's field of view for larger lateral displacements observed in the image plane.

\subsection{Dynamic Analysis of a Cantilever Beam}

A dynamic analysis of a cantilever steel beam is performed using the proposed optical method and an accelerometer. The cantilever beam has a length of $450 \mathrm{~mm}$, a thickness of $1 / 8$ in and a mass $\mathrm{m}$ of $0.3 \mathrm{~kg}$, as shown in Figure 3.

A CMOS camera model EO-0413 with a capture rate of 64 images per second, and a solid-state laser with wavelength in the red spectrum were used for the optical system measurements. A Kistler brand accelerometer model 8640A with a measurement sensitivity of $964 \mathrm{mV} / \mathrm{g}$ in a range of measure of $\pm 5 \mathrm{~g}$ and the sampling frequency used was 2000 samples per second, connected to a data acquisition card of the same brand that saves the acceleration information as a function of time.

The measurement process consists of applying an initial perturbation, at the free end of the beam, and the measurement is carried out with both methods to reconstruct the vibration path, obtaining parameters such as natural frequency, damping coefficient, and its modal shape. 


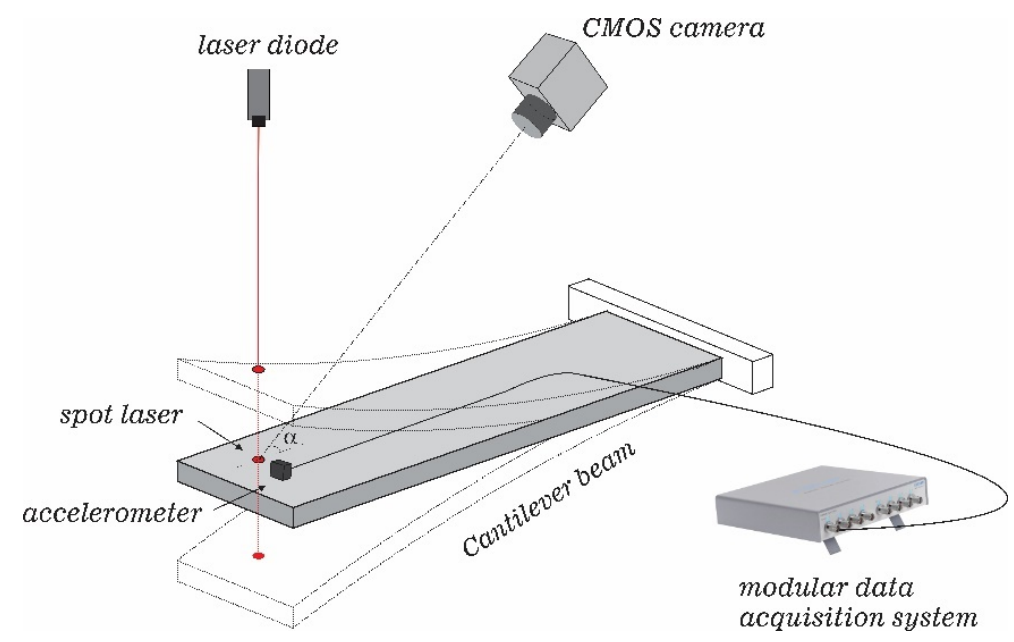

Figure 3. Experimental scheme for dynamic analysis of a cantilever beam.

Using the accelerometer measurements, a set of data was selected in a time interval $\Delta t$, taking as a reference the first maximum amplitude recorded by the equipment. Using the Least Square Complex Exponential method [47-50], this data is fitted to a nonlinear exponential, harmonic equation:

$$
\ddot{x}(t)=A_{b} e^{-\lambda t} \cos (\omega t+\phi)
$$

where $A_{b}$ is the amplitude vibration of the cantilever beam. Specifically, to determine the damping coefficient $c$, we assume that the exponent of decrease $\lambda=c / 2 m$ is known as:

$$
c=2 \lambda m
$$

where $m$ for a continuous system (infinite set of particles) is the equivalent mass, $m_{e q}$.

According to the kinematics of a particle, if we perform the integration of the acceleration as a function of time, we obtain the speed, and a second integration allows us to obtain the displacement values as a function of time. In this way the vibration path is evaluated from the data obtained with the accelerometer.

Unlike the optical method, the vibration paths are obtained directly since the measurements are the displacements observed from a reference plane.

Simultaneous measurements were made with both experimental methods in seven sections of the cantilever beam, where for each data set obtained, a fit was made to reconstruct the vibration path and estimate the coefficients for the model equation used. Additionally, a comparison is presented of the results obtained with both methods, using analytical results as a reference, and highlighting the advantages and disadvantages of the proposed optical method.

\section{Results and Discussion}

\subsection{Analytical Method}

In order to compute modal parameters in an analytical way, the geometry and mechanical properties of a carbon steel beam are considered. The dimensions considered for its geometry are $L=450 \mathrm{~mm}, b=25.53 \mathrm{~mm}, h=3.175 \mathrm{~mm}$; the mass density $\rho=7850 \mathrm{~kg} / \mathrm{m}^{3}$ and the modulus of elasticity, $E=195 \mathrm{GPa}$.

Through Equation (1), we determine the frequency for the first vibration mode $\omega_{1}=12.6235 \mathrm{~Hz}$. On the other hand, solving Equation (7), and substituting in Equation (3), the first modal shape is determined. This result is shown graphically in Figure 4. From the application of Equations (8) and (9), the damping coefficient is $c=0.0205 \mathrm{Ns} / \mathrm{m}$. 


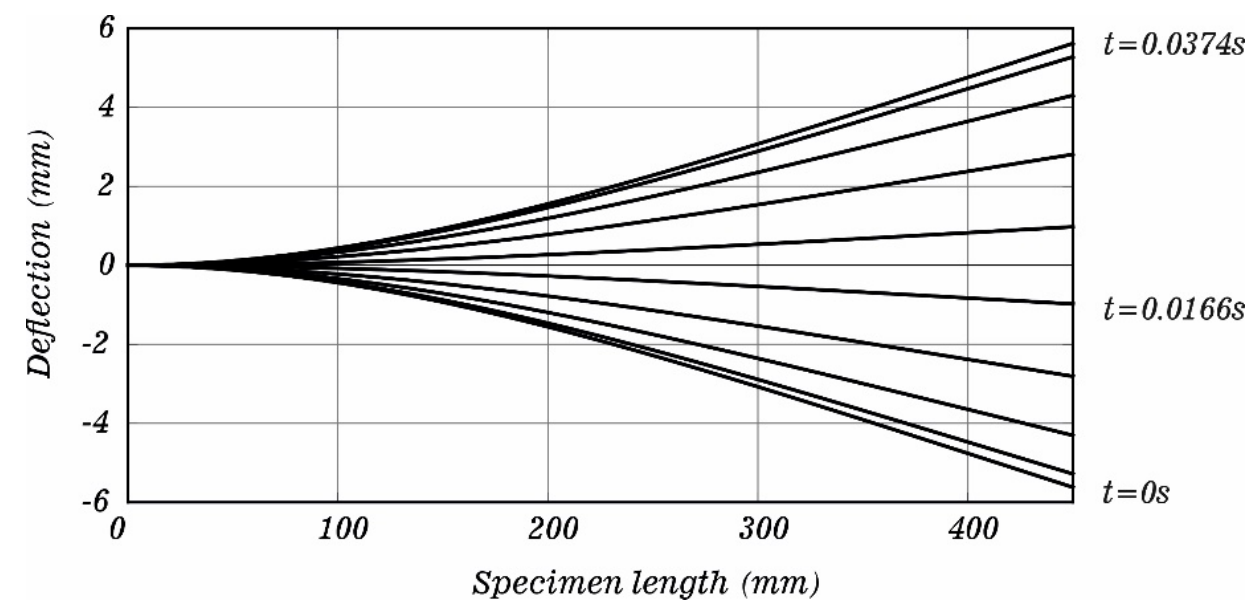

Figure 4. Snapshot of the vibrating cantilevered beam.

\subsection{Accelerometer Method}

A total of 8691 data values were used for analysis, omitting information from unwanted initial readings. Subsequently, the data set was fitted to the model of Equation (11), obtaining the coefficients for the reconstruction of the vibration path and parameters required for the analysis of the dynamic response. Figure 5 shows the superposition of the experimental data from the accelerometer and the graph of the equation obtained with the fit made. It can be seen that the selected time signals contain one clear dominant decaying component. However, the time decay of the signal is not perfectly exponential, as it would be if only one mode would be present, which itself is due to higher order modes of the beam; however, in this work we will only analyze the first vibration mode of the system for validating the optical technique, while other modal forms can be found by measuring the transversal displacements of the system ( $\Delta y^{\prime}$ in the image plane).

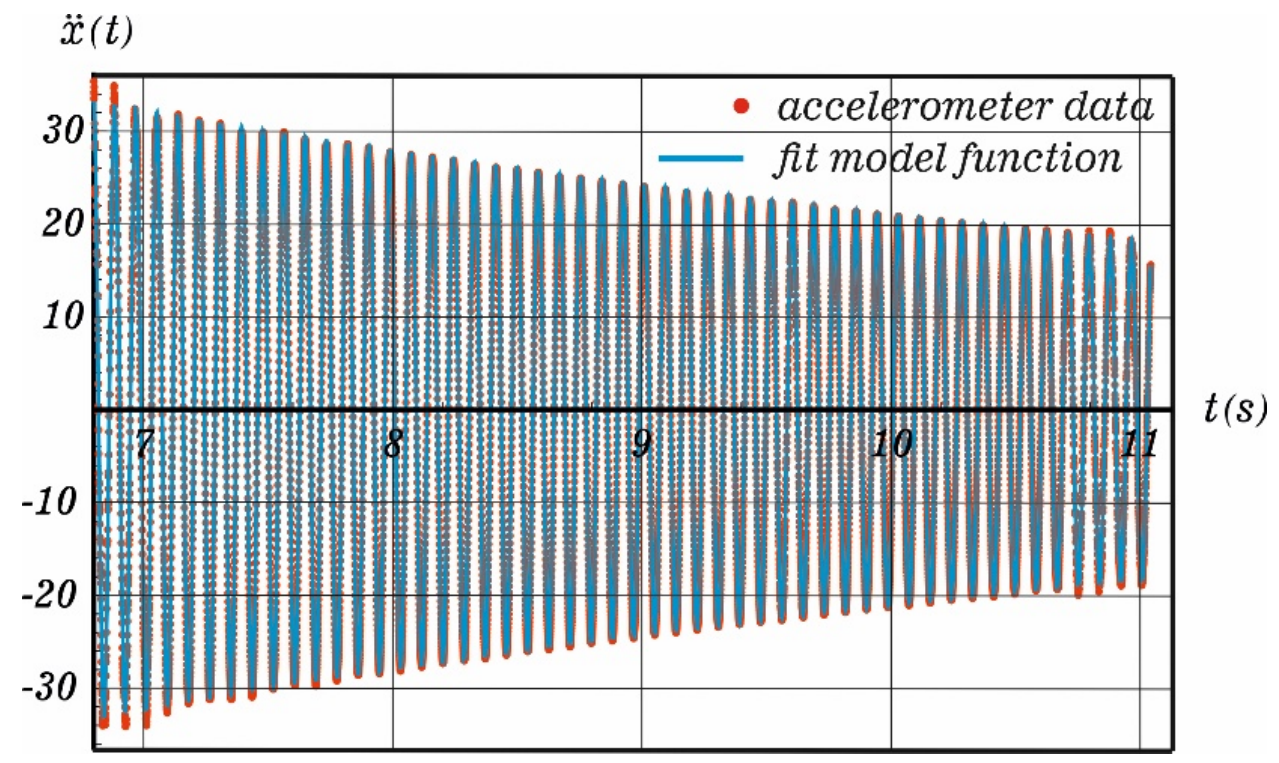

Figure 5. Accelerometer data and fit model function for vibration path reconstruction.

The results shown are from the parameters found in each equation fitted to the model of Equation (11); the frequency is obtained directly by obtaining the parameter $\omega$, with $f=\omega / 2 \pi$, and the damping coefficient $c$ with $c=2 \lambda m$, where $m$ is the mass of the beam. These parameters are the same when the equation that describes the vibration path in units of displacement is obtained, i.e., performing the double integration of the fitting equation. This expression allows us to determine the maximum displacements at any instant of time 
$t$ to reconstruct the modal forms. The Root Mean Square (RMS) results obtained from parameters such as frequency and damping coefficient for the sections measured along the beam were $12.058 \mathrm{~Hz}$ and $0.0211 \mathrm{Ns} / \mathrm{m}$, respectively. The maximum amplitude is obtained at the free end with a magnitude of $5.98 \mathrm{~mm}$ at a time $t$ of $t=6.93 \mathrm{~s}$, which is from the moment that the accelerometer interface begins taking readings.

\subsection{Optical Method}

In the same way as for the accelerometer, a set of the total data are selected starting from the coordinate with the maximum amplitude, for fitting and analysis. A total of 473 data were processed for analysis.

Figure 6 shows the graph overlay of the fitted equation on the selected data. Unlike the results with the accelerometer in the graph, due to the low image capture rate per second (64 fps), some local maximums do not reach the maximum amplitude due to lack of information, which could be a disadvantage of the method. However, the measured adjustment error is comparable with the adjustment error obtained with the accelerometer, of which both are of the order of $1.3 \%$.

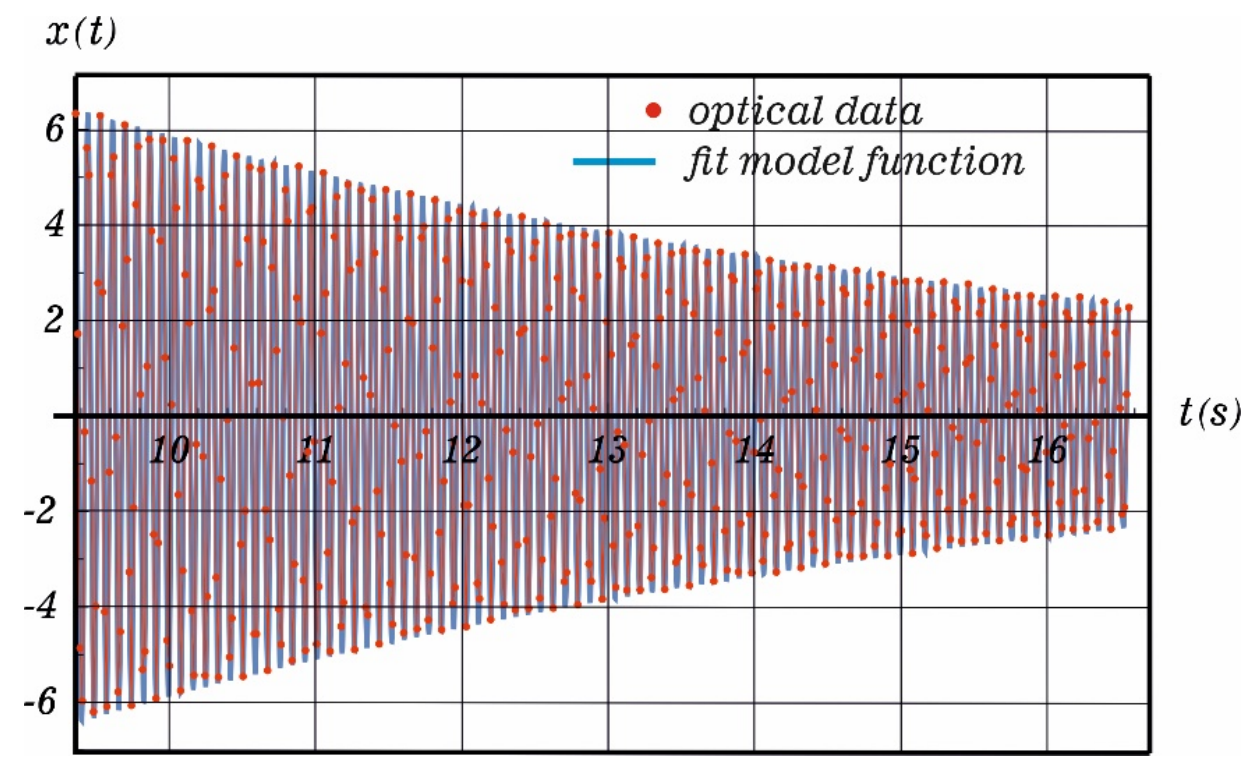

Figure 6. Optical data and fit model function for vibration path reconstruction.

The first maximum obtained at the free end, with this method, has an amplitude of $6.33 \mathrm{~mm}$ at an instant of time $t=9.36 \mathrm{~s}$. The RMS results obtained from parameters such as frequency and damping coefficient for the sections measured along the beam were $12.1611 \mathrm{~Hz}$ and $0.0200 \mathrm{Ns} / \mathrm{m}$ respectively.

We can see that there is a time lag between the two methods $(2.43 \mathrm{~s})$, this due to the start time of each measurement system, but the parameters of interest, for the analysis of the dynamic response, are comparable and discussed in the next section.

\subsection{Reconstruction of the First Vibration Mode}

For the reconstruction of the first vibration mode, the maximum amplitudes are taken in each of the sections measured with both methods. Figure 7 represents the first vibration mode of the steel beam taken from the experimental results with both methods and fitted to a quadratic function, as well as the function obtained with the analytical method. 


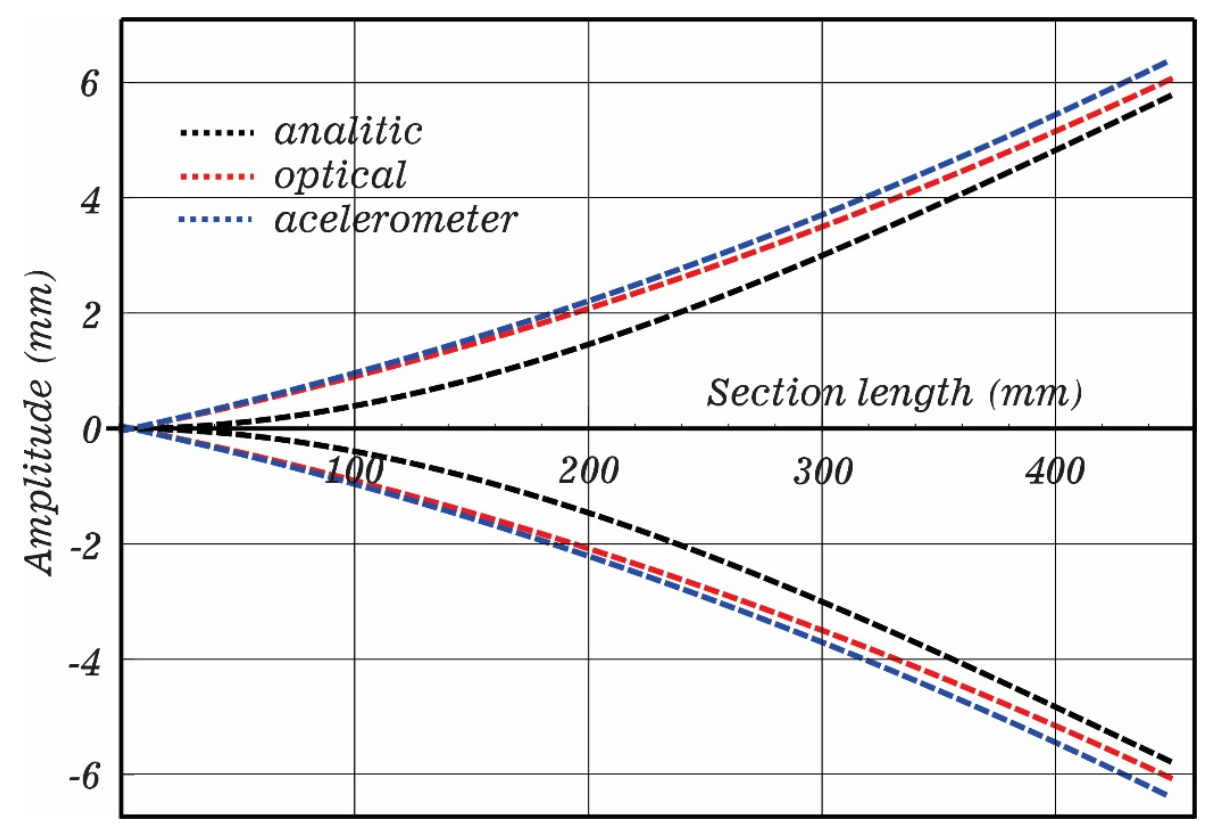

Figure 7. First mode of vibration reconstructed with both experimental techniques and the analytical method.

In this part, the comparison of the experimental methods is performed taking as a reference the analytical result obtained in Section 3.1, to validate if the proposed optical method is a reliable method for dynamic analysis.

Firstly, we analyze the results obtained from the natural frequency parameter with both experimental methods compared with the analytical result. The $\Delta f_{r m s}$ of the differences $\Delta f$ of each of the beam sections measured with both methods was determined, and the analytical result taken as reference value, $f_{\text {ref }}=12.6235 \mathrm{~Hz}$, obtaining the result listed in Table 1.

Table 1. Comparation of frequency and damping coefficient found between the experimental methods for the cantilever beam testing.

\begin{tabular}{ccc}
\hline Methods & $\begin{array}{c}\text { Frequency } \\
(\mathbf{H z})\end{array}$ & $\begin{array}{c}\text { Damping Coefficient } \\
\text { (Ns/m) }\end{array}$ \\
\hline Analytic & 12.6235 & 0.0205 \\
\hline Accelerometer & 12.058 & 0.0211 \\
\hline Optical & 12.1611 & 0.0200 \\
\hline Accelerometer vs. analytic & Differences RMS and Error \% & \\
error (\%) & 0.5655 & 0.0006 \\
Optical vs. analytic & 4.47 & 2.92 \\
error (\%) & 0.4624 & 0.0005 \\
\hline Accelerometer vs. optical & 3.66 & 2.43 \\
error (\%) & 0.1031 & 0.0011 \\
\hline
\end{tabular}

It can be seen that the RMS differences of both methods with respect to the result obtained analytically are comparable, obtaining a better approximation with the optical method, however the reference value (analytical method) is an ideal value, in the mathematical model aerodynamic forces due to the friction between the beam and the air, loss of energy due to the heat and sound generated are omitted. The omission of these variables causes an inaccuracy in the determination of the modal parameters. 
Another result to be compared is the damping coefficient, which can be obtained directly from the fitting equations of both experimental methods, using the value of $\lambda$ and using $c=2 \lambda m$ and $m=m_{e q}$, the damping coefficients are given by $c_{a c e l}=0.0211 \mathrm{Ns} / \mathrm{m}$ and $=0.0200 \mathrm{Ns} / \mathrm{m}$. There is a difference of $0.0011 \mathrm{Ns} / \mathrm{m}$, and again we can see a similarity between the results obtained experimentally between both methods.

A quantitative and qualitative comparison can be obtained by calculating the rms of the differences between both functions. Here we found a difference of the order of $1.08 \mathrm{~mm}$. To show the superposition of both equations (Figure 8), the offset due to the start time in the measurement of each method is compensated.

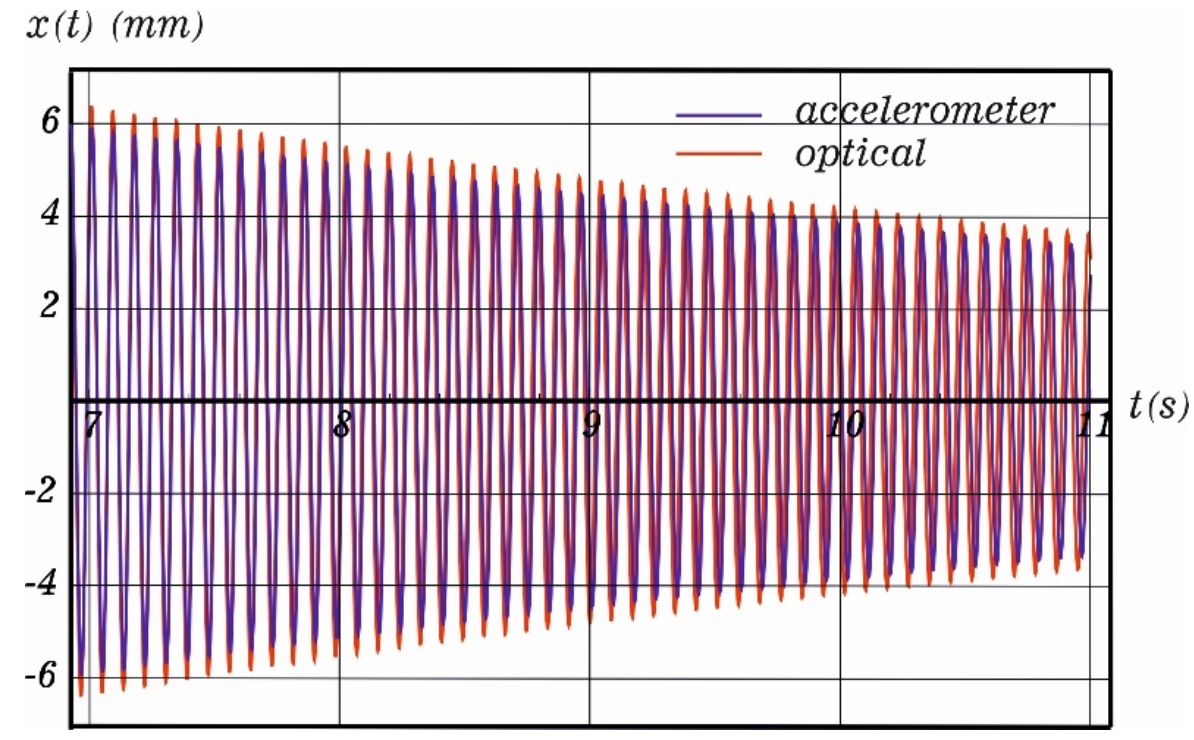

Figure 8. Comparison of displacements amplitude $(x(t))$ as a function of time for both experimental methods.

Finally, we can make a comparison between the experimental methods by obtaining the reconstruction of the first vibration mode, the RMS difference between the fitted quadratic functions of both methods (Figure 8) was of the order of $0.18 \mathrm{~mm}$.

The results shown in the comparison of the two experimental methods, taking the analytical result as a reference, for the determination and analysis of the dynamic response in a free damped system, present evidence of the feasibility of the proposed methodology and the use of the optical method as an alternative technique for the measurement of these useful parameters in the analysis of vibrations of this kind of system.

A similar procedure could be carried out in order to determine the second modal shape, however, one of the disadvantages of the optical method is the limitation in the sampling rate, due to the low capture speed of the camera used (64 fps), compared with the sampling rate of the transducer (2000 samples per second); consequently, the second modal frequency or another's one cannot be computed with the optical method unless a high speed camera is used, increasing the cost of experimental setup. However, an analysis at the limit of the sampling rate for the determination of the frequencies is under study.

\subsection{Experimental Application in a Wind Turbine Blade}

Modal analysis was performed on a low power wind turbine blade manufactured in fiberglass, with an aerodynamic profile FX63137 (Figure 9), $1.7 \mathrm{~m}$ length and a design frequency of $6.6 \mathrm{~Hz}$. The same procedure was used, simultaneous measurements were made in eight sections with the accelerometer and the optical method and the results obtained were compared. The frequency obtained with the accelerometer was $7.62 \mathrm{~Hz}$ and with the optical method $7.93 \mathrm{~Hz}$, the rms value between these differences was $0.31 \mathrm{~Hz}$. The damping coefficients were $2.60 \mathrm{Ns} / \mathrm{m}$ with the accelerometer and $2.79 \mathrm{Ns} / \mathrm{m}$ with 
the optical method. In addition, the reconstruction of the first vibration mode with both experimental techniques is shown in Figure 10. The RMS difference between the fitted quadratic functions of both methods was of the order of $0.16 \mathrm{~mm}$. In Table 2 we show a comparison between the frequencies and damping coefficients computed by both methods.

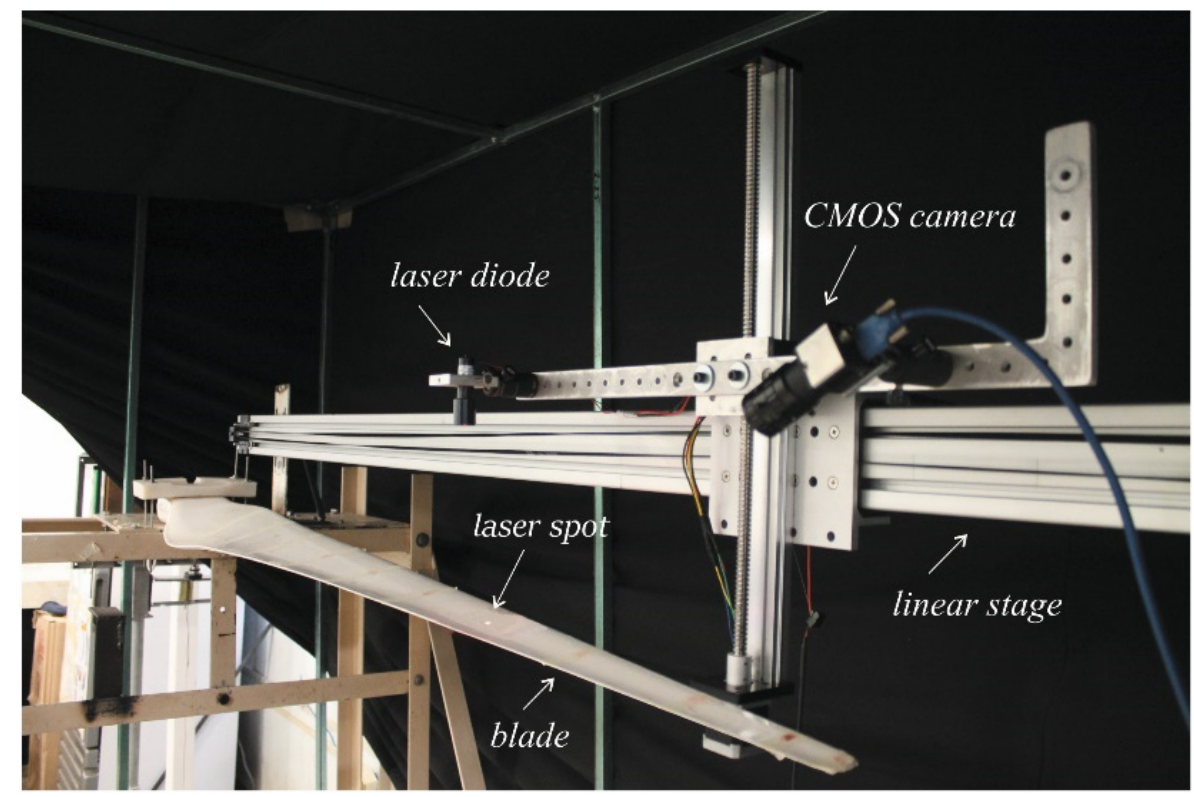

Figure 9. Test of a wind turbine blade with profile FX63137.

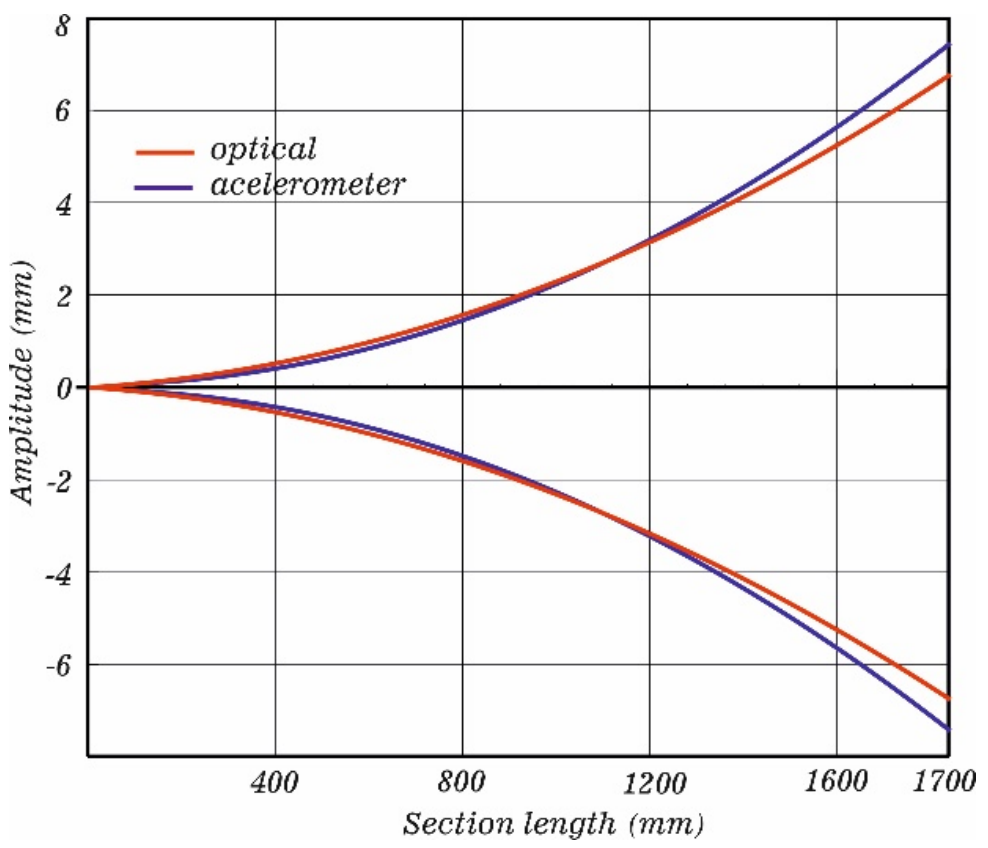

Figure 10. First mode of vibration of the wind turbine blade with both experimental techniques. 
Table 2. Comparation of frequency and damping coefficient found between the experimental methods for the wind turbine blade.

\begin{tabular}{ccc}
\hline Methods & $\begin{array}{c}\text { Frequency } \\
(\mathbf{H z})\end{array}$ & $\begin{array}{c}\text { Damping Coefficient } \\
\text { (Ns/m) }\end{array}$ \\
\hline Accelerometer & 7.62 & 2.60 \\
\hline Optical & 7.93 & 2.79 \\
\hline Accelerometer vs. optical & Differences RMS and Error \% & \\
error (\%) & 0.31 & 0.19 \\
\hline
\end{tabular}

In this experimental application, the laser spot is projected on the surface of the wind turbine blade under test, it is important to mention that although the geometry of the cross-section is not constant, the nature of the deformation remains unchanged at any point of the vibration measurement, this allows to apply the same procedure used in the cantilever beam testing. The measurement system can be displaced along any section of interest for blades up to $3 \mathrm{~m}$ in length. Similarly, due to the low sampling rate of the camera used in optical technique only the first frequency can be computed.

\section{Conclusions}

Optical techniques are being increasingly used to measure vibrations, and it is important to continue to research improvements for these techniques to increase the efficiency and precision of the measurement of parameters of interest.

The technique and methodology presented in this work offers an alternative to be implemented in a wind turbine blade testing system and to replace those common commercial sensors that are used for this type of tests, such as accelerometers or laser vibrometers which have a high cost in the market. The results presented with the optical technique show a good comparison with the accelerometer data and the analytical results. There is a large discrepancy in the estimation of the natural frequency, when the results are compared with the analytical method (3.66\%); this is because these analytical parameters are ideal and some factors, as mentioned before, such as friction forces, energy loss due to heat, sound, among other disturbances, are not considered. However, there is a low discrepancy if we compare the results of the optical method with the traditional transducer (accelerometer) used as a reference, and we obtain a value $<1 \%$, which is an acceptable result if we consider the international standard (ISO-16063) of Montalvão 2014 [50].

This slight discrepancy is due to the low sampling density of the camera used (64 fps) compared to the density of the accelerometer; however, the estimation of the fit and results are reasonable, but it can be improved with a camera with a high density of sampling.

The optical technique applied in this study revealed a simple method than can be adapted as a vibration measurement system of large wind turbine blades. However, the methodology presented can be applied to other systems that present geometric and mechanical symmetry, and it is possible to split the mathematical analysis with a model for symmetric modes of vibration in these systems.

Author Contributions: Conceptualization, V.I.M.-O., O.F.-D., E.R.-H., M.C.-G., E.C.-M., J.R.D.-P., Q.H.-E., J.A.F., A.-J.P.-M. and A.A.G.; methodology, V.I.M.-O., O.F.-D., E.R.-H., M.C.-G., E.C.-M., J.R.D.-P., Q.H.-E., J.A.F., A.-J.P.-M. and A.A.G.; investigation, V.I.M.-O., O.F.-D., E.R.-H., M.C.-G., E.C.-M., J.R.D.-P., Q.H.-E., J.A.F., A.-J.P.-M. and A.A.G.; writing-original draft preparation, V.I.M.-O., O.F.-D., E.R.-H., M.C.-G., E.C.-M., J.R.D.-P., Q.H.-E., J.A.F., A.-J.P.-M. and A.A.G.; writing-review and editing, V.I.M.-O., O.F.-D., E.R.-H., M.C.-G., E.C.-M., J.R.D.-P., Q.H.-E., J.A.F., A.-J.P.-M. and A.A.G. All authors have read and agreed to the published version of the manuscript.

Funding: This research received no external funding.

Institutional Review Board Statement: Not applicable. 
Informed Consent Statement: Not applicable.

Data Availability Statement: We don't report any data. Please exclude this statement.

Acknowledgments: The authors of this paper are indebted to Neil Bruce (Instituto de Ciencias Aplicadas y Tecnología, Universidad Nacional Autónoma de México, México), for his help in revising the manuscript.

Conflicts of Interest: The authors declare no conflict of interest.

\section{References}

1. Farsadi, T. Enhancement of Static and Dynamic Performance of Composite Tapered Pretwisted Rotating Blade with Variable Stiffness. J. Vib. Acoust. 2020, 143, 143. [CrossRef]

2. Edrah, M.; Zhao, X.; Hung, W.; Qi, P.; Marshall, B.; Karcanias, A.; Baloch, S. Effects of POD Control on a DFIG Wind Turbine Structural System. IEEE Trans. Energy Convers. 2020, 35, 765-774. [CrossRef]

3. Dilek, A.U.; Oguz, A.D.; Satis, F.; Gokdel, Y.D.; Ozbek, M. Condition monitoring of wind turbine blades and tower via an automated laser scanning system. Eng. Struct. 2019, 189, 25-34. [CrossRef]

4. Yang, Y.; Dorn, C.; Farrar, C.; Mascareñas, D. Blind, simultaneous identification of full-field vibration modes and large rigid-body motion of output-only structures from digital video measurements. Eng. Struct. 2020, 207, 110183. [CrossRef]

5. Al-Hadad, M.; McKee, K.K.; Howard, I. Vibration characteristic responses due to transient mass loading on wind turbine blades. Eng. Fail. Anal. 2019, 102, 187-202. [CrossRef]

6. Wang, W.; Li, X.; Ahmat, Y.; Hu, X.; Chen, A. Vibration measurement method based on point tracking for irregular structures. Optik 2019, 176, 482-490. [CrossRef]

7. Franco-Piña, J.A.; Contreras, L.; Jauregui, J.C. Real Time Conditioning Monitoring for Failure Prediction. In Turbo Expo: Power for Land, Sea, and Air; ASME International: New York, NY, USA, 2017; Volume 9.

8. Von Martens, H.J. Metrology of vibration measurements by laser techniques. In Eighth International Conference on Vibration Measurements by Laser Techniques: Advances and Applications; International Society for Optics and Photonics: Bellingham, DC, USA, 2008.

9. Proulx, T. Structural Dynamics and Renewable Energy; Conference Proceedings of the Society for Experimental Mechanics Series; Springer: New York, NY, USA, 2011; Volume 1, ISBN 978-1-4419-9716-6.

10. Proulx, T. Structural Dynamics; Conference Proceedings of the Society for Experimental Mechanics Series; Springer: New York, NY, USA, 2011; Volume 3, ISBN 978-1-4419-9834-7.

11. Proulx, T. Rotating Machinery, Structural Health Monitoring, Shock and Vibration; Conference Proceedings of the Society for Experimental Mechanics Series; Springer: New York, NY, USA, 2011; Volume 1, ISBN 978-1-4419-9428-8.

12. Castellini, P.; Santolini, C. Vibration measurements on blades of a naval propeller rotating in water with tracking laser vibrometer. Measurement 1998, 24, 43-54. [CrossRef]

13. Moreno, D.; Barrientos, B.; Pérez-López, C.; Mendoza-Santoyo, F. Modal vibration analysis of a metal plate by using a laser vibrometer and the POD method. J. Opt. A Pure Appl. Opt. 2005, 7, S356-S363. [CrossRef]

14. Siringoringo, D.M.; Fujino, Y. Noncontact Operational Modal Analysis of Structural Members by Laser Doppler Vibrometer. Comput. Civ. Infrastruct. Eng. 2009, 24, 249-265. [CrossRef]

15. Perrone, G.; Vallan, A. A Low-Cost Optical Sensor for Noncontact Vibration Measurements. IEEE Trans. Instrum. Meas. 2008, 58, 1650-1656. [CrossRef]

16. García, Y.R.; Corres, J.M.; Fernández, J.G. Vibration Detection Using Optical Fiber Sensors. J. Sens. 2010, 2010, 1-12. [CrossRef]

17. Larsson, H.; Hertegård, S. Calibration of high-speed imaging by laser triangulation. Logop. Phoniatr. Vocol. 2004, $29,154-161$. [CrossRef]

18. Wu, J.-H.; Chang, R.-S.; Jiang, J.-A. A Novel Pulse Measurement System by Using Laser Triangulation and a CMOS Image Sensor. Sensors 2007, 7, 3366-3385. [CrossRef]

19. Chen, Y.-Y.; Chang, R.-S.; Tsai, M.-Y.; Chen, D.-C. The Optical Measurement and Quantitative Analysis of Algesia in Spodoptera litura Larva. J. Opt. Soc. Korea 2015, 19, 169-174. [CrossRef]

20. Yang, H.; Tao, W.; Zhang, Z.; Zhao, S.; Yin, X.; Zhao, H. Reduction of the Influence of Laser Beam Directional Dithering in a Laser Triangulation Displacement Probe. Sensors 2017, 17, 1126. [CrossRef]

21. Ueda, M.; Yamaguchi, T.; Kakiuchi, H.; Suga, H. A simple optical method for measuring the vibration amplitude of a speaker. Opt. Lasers Eng. 1999, 32, 21-28. [CrossRef]

22. Moreno-Oliva, V.I.; Román, E.; Torres-Moreno, E.; Dorrego-Portela, J.R.; Avendaño-Alejo, M.; Campos-García, M.; SánchezSánchez, S. Measurement of quality test of aerodynamic profiles in wind turbine blades using laser triangulation technique. Energy Sci. Eng. 2019, 7, 2180-2192. [CrossRef]

23. Zhang, G.; He, J.; Li, X. 3D vision inspection for internal surface based on circle structured light. Sens. Actuators A Phys. 2005, 122, 68-75. [CrossRef]

24. Son, S.; Park, H.; Lee, K.H. Automated laser scanning system for reverse engineering and inspection. Int. J. Mach. Tools Manuf. 2002, 42, 889-897. [CrossRef] 
25. Sansoni, G.; Trebeschi, M.; Docchio, F. State-of-The-Art and Applications of 3D Imaging Sensors in Industry, Cultural Heritage, Medicine, and Criminal Investigation. Sensors 2009, 9, 568-601. [CrossRef] [PubMed]

26. Schwenke, H.; Neuschaefer-Rube, U.; Pfeifer, T.; Kunzmann, H. Optical Methods for Dimensional Metrology in Production Engineering. CIRP Ann. 2002, 51, 685-699. [CrossRef]

27. Zhang, H.; Ren, Y.; Liu, C.; Zhu, J. Flying spot laser triangulation scanner using lateral synchronization for surface profile precision measurement. Appl. Opt. 2014, 53, 4405-4412. [CrossRef]

28. Rivera-Ortega, U.; Dirckx, J.; Meneses-Fabian, C. Fully automated low-cost setup for fringe projection profilometry. Appl. Opt. 2015, 54, 1350-1353. [CrossRef]

29. Cao, P.; Xi, J.; Yu, Y.; Guo, Q.; Song, L. 3D shape measurement based on projection of triangular patterns of two selected frequencies. Opt. Express 2014, 22, 29234-29248. [CrossRef] [PubMed]

30. Baqersad, J.; Poozesh, P.; Niezrecki, C.; Avitabile, P. Photogrammetry and optical methods in structural dynamics-A review. Mech. Syst. Signal Process. 2017, 86, 17-34. [CrossRef]

31. Chang, C.-C.; Ji, Y.F. Flexible Videogrammetric Technique for Three-Dimensional Structural Vibration Measurement. J. Eng. Mech. 2007, 133, 656-664. [CrossRef]

32. Ozbek, M.; Rixen, D. Operational modal analysis of a $2.5 \mathrm{MW}$ wind turbine using optical measurement techniques and strain gauges. Wind. Energy 2012, 16, 367-381. [CrossRef]

33. Warren, C.; Niezrecki, C.; Avitabile, P. Optical Non-Contacting Vibration Measurement of Rotating Turbine Blades II; Structural Dynamics and Renewable Energy; Springer: New York, NY, USA, 2011; Volume 1, ISBN 978-1-4419-9716-6.

34. Ozbek, M.; Rixen, D.J.; Erne, O.; Sanow, G. Feasibility of monitoring large wind turbines using photogrammetry. Energy 2010, 35, 4802-4811. [CrossRef]

35. Sutton, M.A.; Orteu, J.J.; Schreier, H. Image Correlation for Shape, Motion and Deformation Measurements: Basic Concepts, Theory and Applications; Springer Science \& Business Media: Cham, Switzerland, 2009; ISBN 0-387-78747-X.

36. Liu, T.; Burner, A.W.; Jones, T.W.; Barrows, D.A. Photogrammetric techniques for aerospace applications. Prog. Aerosp. Sci. 2012, 54, 1-58. [CrossRef]

37. Su, X.; Zhang, Q. Dynamic 3-D shape measurement method: A review. Opt. Lasers Eng. 2010, 48, 191-204. [CrossRef]

38. Feng, D.; Feng, M.Q. Computer vision for SHM of civil infrastructure: From dynamic response measurement to damage detection-A review. Eng. Struct. 2018, 156, 105-117. [CrossRef]

39. Zona, A. Vision-Based Vibration Monitoring of Structures and Infrastructures: An Overview of Recent Applications. Infrastructures 2020, 6, 4. [CrossRef]

40. Dong, C.-Z.; Catbas, F.N. A review of computer vision-based structural health monitoring at local and global levels. Struct. Health Monit. 2021, 20, 692-743. [CrossRef]

41. Jiang, R.; Jáuregui, D.V.; White, K.R. Close-range photogrammetry applications in bridge measurement: Literature review. Measurement 2008, 41, 823-834. [CrossRef]

42. Berkovic, G.; Shafir, E. Optical methods for distance and displacement measurements. Adv. Opt. Photon. 2012, 4, 441-471. [CrossRef]

43. Singiresu, S.R. Mechanical Vibrations; Addison Wesley: Boston, MA, USA, 1995; ISBN 0-201-52686-7.

44. Asmar, N.H. Partial Differential Equations with Fourier Series and Boundary Value Problems; Courier Dover Publications: Mineola, NY, USA, 2016; ISBN 0-486-80737-1.

45. Kelly, S.G. Mechanical Vibrations: Theory and Applications; Cengage Learning: Stamford, CT, USA, 2012; ISBN 1-4390-6214-5.

46. Ugural, A.C.; Fenster, S.K. Advanced Strength and Applied Elasticity; Pearson Education: London, UK, 2003; ISBN 0-13-244052-0.

47. Zrayka, A.K.; Mucchi, E. A comparison among modal parameter extraction methods. SN Appl. Sci. 2019, 1, 781. [CrossRef]

48. Brown, D.L.; Allemang, R.J.; Zimmerman, R.; Mergeay, M. Parameter Estimation Techniques for Modal Analysis. SAE Tech. Pap. Ser. 1979, 88, 828-846. [CrossRef]

49. Richardson, M.H.; Formenti, D.L. Parameter Estimation from Frequency Response Measurements Using Rational Fraction Polynomials; Union College Schenectady: Schenectady, NY, USA, 1982; Volume 1, pp. 167-186.

50. Montalvão, D.; Silva, J. A Contribution to the Modal Identification of the Damping Factor Based on the Dissipated Energy. In Proceedings of the International Conference on Structural Dynamic, EURODYN 2014, 9th International Conference on Structural Dynamics, Porto, Portugal, 30 June-2 July 2014; Volume 2014. 